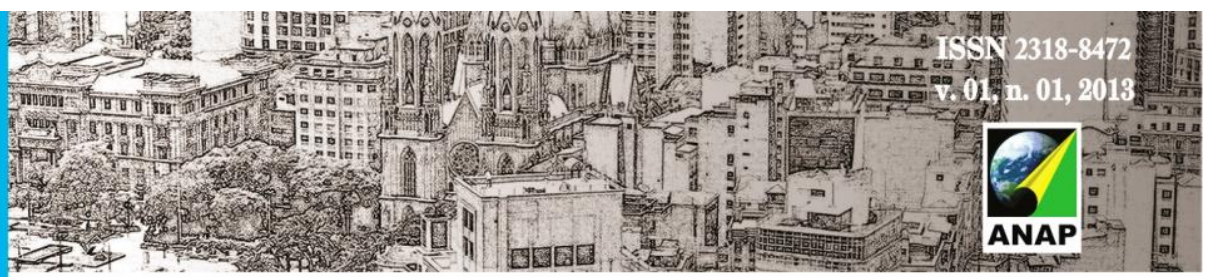

Revista Nacional de

Gerenciamento de Cidades

\title{
O VALOR DO DESENHO URBANO NA CONFORMAÇÃO DE TERRITÓRIOS HABITACIONAIS
}

\author{
Dina De Paoli
}

Silvia Mikami G. Pina

RESUMO: Esse artigo vem colocar em discussão a potencialidade do Desenho Urbano em agregar valor a territórios habitacionais, a fim de contribuir para a melhora qualitativa desses conjuntos e suas vizinhanças e para que os territórios habitacionais ofereçam mais qualidade de vida. Assim, o objetivo desse artigo é verificar como o desenho urbano pode atuar como elemento gerador de valor não apenas financeiro, mas valor social, cultural e ambiental em áreas habitacionais, produzindo assim um ambiente urbano de qualidade. $O$ valor do desenho urbano é determinado pelas caraterísticas espaciais de contexto e pela relação que o usuário tem com ele, dos benefícios e sacrifícios que ele obtém quando usufrui desse espaço, porém enquadrado em seus próprios valores. Um dos instrumentos sugeridos nesse artigo para identificar o valor do Desenho Urbano é o guia formulado pela Comissão de Arquitetura e do Ambiente Construído da Inglaterra, denominado Building for Life, que apresenta critérios e diretrizes que podem ser utilizadas na etapa do processo de projeto de conjuntos habitacionais, para incrementar sua 


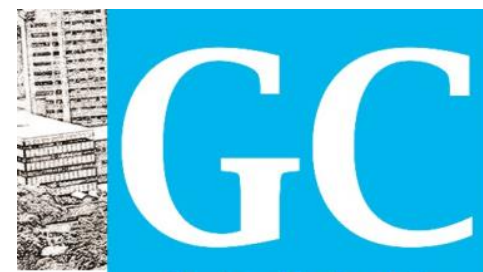

Revista Nacional de

Gerenciamento de Cidades

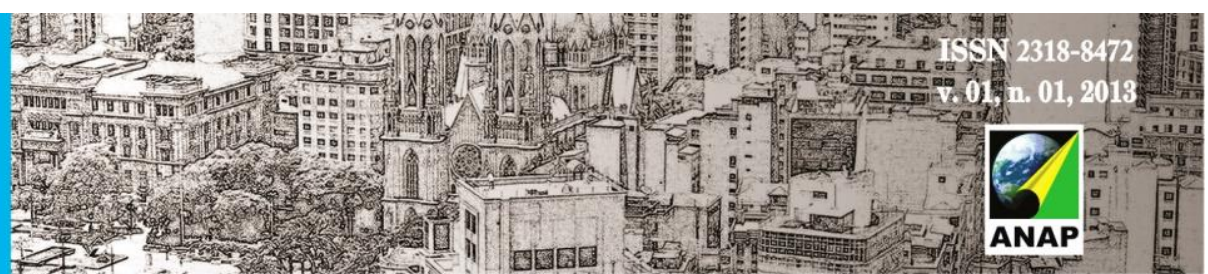

qualidade e potencialidade. $\mathrm{O}$ instrumento é aplicado em dois projetos premiados como exemplos de sua validade.

Palavras-chave: Território habitacional. Desenho urbano. Valor.

\section{INTRODUÇÃO}

A década de 1960 foi marcada pelas primeiras criticas sobre a qualidade do ambiente urbano produzido até então, tanto pelo poder público como pela inciativa privada, que provocaram um repensar da forma como as cidades vinham se desenvolvendo até aquele momento. É nesse cenário que o Desenho Urbano se consolidaria enquanto campo de conhecimento das relações complexas entre o ser humano e todos os elementos do espaço construído e não construído (CARMONA, 2001), onde os valores, constituídos pelas necessidades humanas, influenciam os espaços e 0 cotidiano das pessoas e o torna um elemento gerador de valores sociais, culturais, ambientais e econômicos, com o objetivo de melhorar a qualidade de vida nas cidades. Desse modo, o desenho urbano estabeleceu-se como conceito onde a qualidade de vida no ambiente construído é prioridade, sendo um dos responsáveis pela produção de lugares que possibilitem as pessoas aproveita-los e usá-los em sua capacidade máxima, pensando na escala humana e nas necessidades de seus usuários. Tornando espaços urbanos valorizados e carregados de significados.

O objetivo desse artigo é verificar como o desenho urbano pode atuar como elemento gerador de valor, não só financeiro, mas valor social, cultural e ambiental em áreas habitacionais, produzindo assim um ambiente urbano de qualidade. Um dos instrumentos sugeridos para identificar o valor do Desenho Urbano é o guia formulado pela Comissão de Arquitetura e do Ambiente Construído (Commission for Architecture and the Built Environment - CABE), da Inglaterra, denominado Building for Life, com 


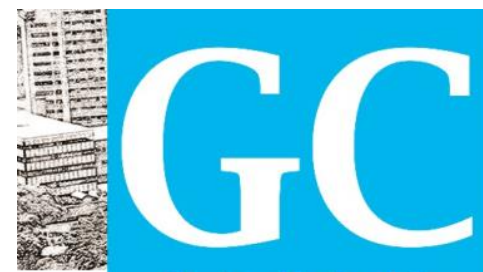

Revista Nacional de

Gerenciamento de Cidades

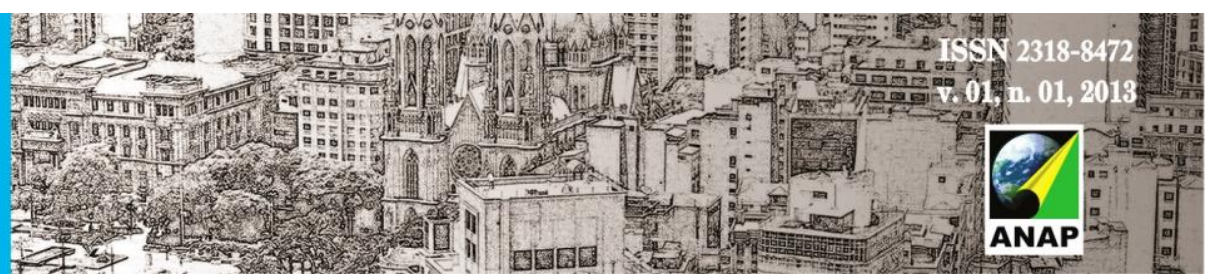

critérios e diretrizes que podem ser utilizados no momento de projetar conjuntos habitacionais, verificando sua qualidade e potencialidade. Dois projetos premiados são apresentados brevemente, com a intenção de demonstrar como elementos presentes no guia BFL e verificados nos dois conjuntos construídos em Londres, podem contribuir para ambientes construídos com vitalidade e gerar valor tanto social, ambiental quanto econômico.

\section{DESENHO URBANO}

O desenho urbano apareceu como campo disciplinar de conhecimento, com o objetivo de preencher o espaço de transição existente entre a escala da Arquitetura e do Planejamento Urbano (FERNANDES, 2009, p.50), fazendo a ponte entre os dois, pois segundo Macedo (1984) a Arquitetura é considerada uma disciplina mais ligada ao entendimento do ambiente construído e o Planejamento ao gerenciamento da vida urbana. Dessa forma o desenho urbano trata o espaço urbano em sua dimensão mais evidente para a população: o espaço vivencial público do seu cotidiano (DEL RIO, 1990), onde o espaço urbano é o suporte das atividades que ali acontecem.

Carmona et al. (2001) considera o desenho urbano como o conjunto das relações complexas entre todos os elementos do espaço construído e não construído: a relação entre diferentes edifícios, entre os edifícios e as ruas, praças, parques e margens de rios e todo tipo de espaço público, a relação entre a parte de uma vila, bairro ou cidade com outras partes e o padrão de movimentos e atividades ali estabelecidos, além de focar na natureza e na qualidade do espaço público. Portanto, o termo urbano possui um amplo significado, que abrange além das cidades, as vilas e os bairros, enquanto desenho, ao invés de ser uma mera interpretação estética, é muito mais a efetiva solução e/ou o processo de produção e organização dos espaços (CARMONA ET AL, 2003). Assim, o desenho urbano, trata da dimensão físico-ambiental da cidade, enquanto conjunto de 


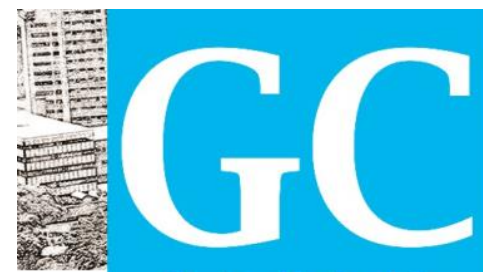

Revista Nacional de

Gerenciamento de Cidades

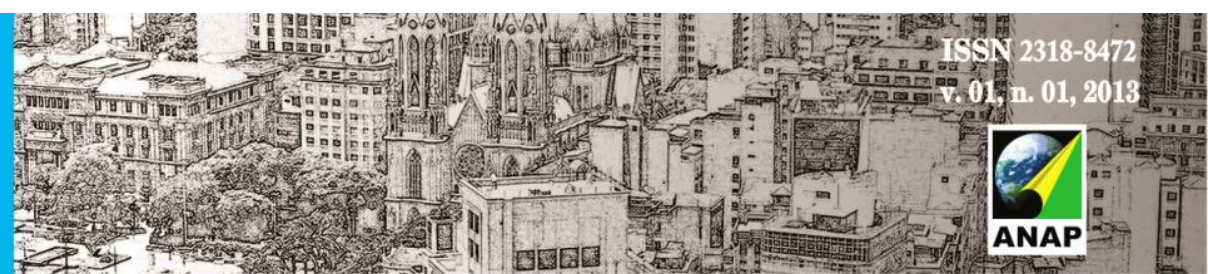

sistemas físico-espaciais e sistemas de atividades que interagem com a população através de suas vivências, percepções e ações cotidianas (DEL RIO, 1990). Enfim, é um processo que estuda a relação homem/meio considerando as dimensões espaciais, temporais e sociais, mas também, como a arquitetura, considera questões estéticas, funcionais e perceptivas (FERNANDES, 2009).

Portanto, o termo desenho urbano estabeleceu-se como conceito onde a qualidade de vida nos espaços públicos é prioridade, tanto como elemento físico quanto sócio cultural, responsável pela produção de lugares que possibilitem às pessoas aproveitá-los e usá-los em sua capacidade máxima. Atualmente, o desenho urbano somou as suas preocupações às questões do desenvolvimento sustentável, priorizando a escala humana e a menor dependência dos recursos naturais não renováveis, respeitando e conservando o meio ambiente natural, valorizando o pedestre e a interação dos vários meios de transporte não poluentes e priorizando a utilização e redesenho de áreas com infraestruturas consolidadas. Ainda assim, o desenho urbano é pouco valorizado no cotidiano das pessoas, que apenas o valorizam quando percebem a sua ausência, uma vez que já tenham vivenciado espaços de qualidade. Até mesmo os profissionais responsáveis por projetar e construir espaços, por vezes o ignoram, sem reconhecer que o desenho urbano, além de agregar valor financeiro, agrega sustentabilidade, valores sociais, culturais e ambientais.

\section{VALOR MULTIDIMENSIONAL}

Alguns estudos de Valor já foram desenvolvidos. Na área de marketing (MIRON, 2008), considera-se a percepção de valor pelo cliente como a ponderação entre os benefícios recebidos pela aquisição do produto ou serviço e os sacrifícios percebidos ao se confrontar o preço destes. Já os economistas colocam a questão do valor de forma 

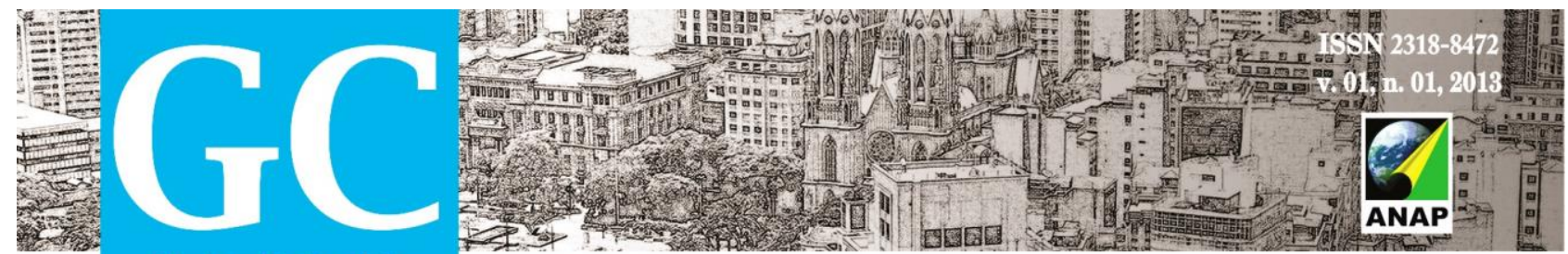

Revista Nacional de

Gerenciamento de Cidades

simplificada, onde o valor das coisas está perfeitamente refletido pelo dinheiro ou tempo gasto para obtê-las e usá-las. Neste caso, valor é igual a dinheiro, uma visão limitada do conceito, onde o dinheiro pode ser um valor, mas não o único (BENEDIKT, 2003). Tanto a visão da área de marketing como da economia são insuficientes para a reflexão que se pretende e seria pertinente buscar alternativas no sentido de se quantificar o valor por meio de desejos, considerando, atributos ou preferências, que influenciam na relação do ser humano com seu ambiente construído, a partir da própria visão do indivíduo.

O Valor é subjetivo e multidimensional, é preciso entender e discutir seu conceito para melhor empregar o termo. A determinação do Valor de algo depende de quem o está julgando, de quantas pessoas estão envolvidas nesse julgamento e a relação desses diferentes pontos de vista. Valor é um assunto pessoal, não um fato objetivo, são princípios escolhidos por cada um para viver. O que se valoriza tem origem nos valores que cada um carrega e escolhe para acreditar, são crenças, princípios morais e ideais dos indivíduos e estão refletidos nas suas atitudes e comportamentos dentro da sociedade (THOMSON ET AL. 2003, SAXON, 2005).

Segundo Benedikt (2003), o Valor tem origem em questões básicas do ser humano e se apresenta através de um sentimento de necessidades intimamente relacionadas e organizadas de forma hierarquizada de importância; quando uma necessidade é saciada outra aparece, dominando a consciência humana e organizando o comportamento do indivíduo. Por tanto, o Valor aqui nesse artigo é apresentado por meio das necessidades humanas e na perspectiva da compreensão de como o Desenho Urbano pode responder a essas necessidades, produzindo um ambiente construído com os valores de seus usuários refletidos em seus espaços. Uma pesquisa realizada pelo grupo BLIND REVIEW analisou a natureza do valor desejado pelos usuários de Empreendimentos de Habitação de Interesse Social, a fim de verificar a potencialidade do conceito de valor desejado para introdução de melhorias nos projetos habitacionais e seus processos, com o objetivo de aumentar a qualidade de tais empreendimentos, focando a unidade habitacional (GRANJA ET AL. 2009) e ao relacionar este conceito de valor desejado aos 


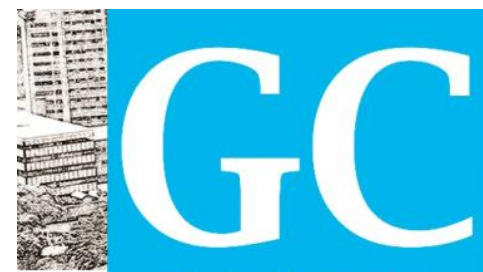

Revista Nacional de

Gerenciamento de Cidades

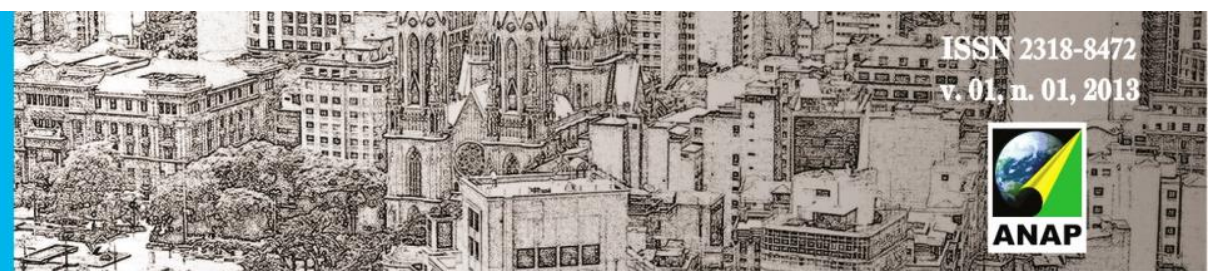

empreendimentos habitacionais, colocou em evidencia como ele pode imprimir qualidade ao associar-se ao todo da habitação por meio do desenho urbano.

\section{O DESENHO URBANO COMO VALOR EM TERRITÓRIOS HABITACIONAIS}

Algumas das áreas mais valorizadas das cidades são sobreviventes de momentos de um bom desenho urbano, permanecendo com uma boa percepção de qualidade e um bom retorno de investimentos através de décadas. São áreas como essas que demonstram como um projeto urbano e arquitetônico e um desenho urbano de qualidade podem produzir espaços que perdurem gerando valor aos moradores, usuários e proprietários, demonstrando sua importância no conjunto de benefícios para os inúmeros agentes envolvidos na produção e uso do ambiente construído (CARMONA ET AL. 2002, McINDOE ET AL. 2005).

Portanto, se faz necessário continuar a discussão sobre o papel do Desenho urbano como elemento gerador de valor sócio economico em projetos e empreendimentos de escala urbana. Porém, o valor em sua multidimensionalidade engloba também questões que vão além do valor econômico.

Thomson et al. (2003) coloca o valor como a relação entre conseqüências positivas e negativas (benefícios e sacrifícios), onde o valor não existe por sí só, mas é o acesso à algo, onde esse acesso depende de um contexto e suas características e resume: o valor do desenho urbano é então determinado pelo espaço (contexto) e pela relação que o usuário tem com ele, dos benefícios e sacrifícios que ele obtém quando usufrui desse espaço, porém enquadrado em seus próprios valores. Ao mesmo tempo, Benedikt (2008) diz que, são as necessidades humanas: sobrevivência, segurança, legitimidade, aprovação, confiança e liberdade, que deveriam ser o foco da arquitetura e do desenho urbano na hora de projetar os espaços do ambiente construído a fim de melhorar a 


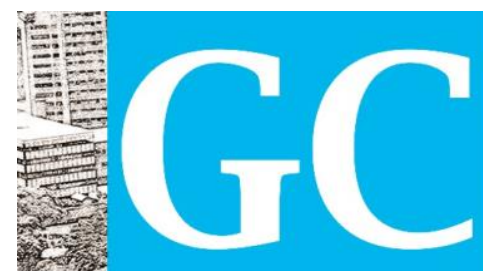

Revista Nacional de

Gerenciamento de Cidades

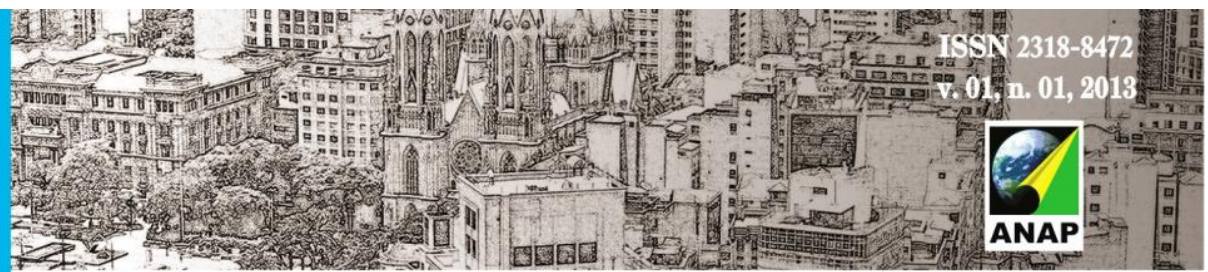

qualidade de vida das pessoas.

Os benefícios do desenho urbano de qualidade na forma de maior valor financeiro do bem material podem ser rapidamente avaliados através dos benefícios diretos traduzidos em valor monetário de mercado, mas o mesmo não acontece com os benefícios indiretos que influenciam social e ambientalmente, pois não podem ser mensurados através de técnicas de avaliação (CARMONA ET AL.2002). Esses benefícios também podem ser divididos em valores tangíveis e mensuráveis e valores intangíveis. Por tanto, uma das dificuldades em se tratar de valor e desenho urbano, está relacionada às questões econômicas e as questões humanas, que juntas são responsáveis em criar um todo que pode ser melhor que a soma de suas partes (McINDOE ET AL. 2005, p.06).

Carmona et al. (2002) ressalta que existem dificuldades conceituais e práticas no momento de estimar o valor do desenho urbano e para isso seria melhor usar uma visão mais geral e o senso comum dos envolvidos na produção do espaço, incluindo a apreciação qualitativa de como diferentes usuários percebem o valor do desenho urbano e dados quantitativos disponíveis do sucesso ou não do ambiente em questão. Assim se torna necessário o desenvolvimento de parâmetros para uma visão mais completa do valor do desenho urbano, buscando o desenvolvimento sustentável e a melhora da qualidade de vida (CARMONA ET AL. 2002).

\section{A INICIATIVA DO REINO UNIDO: BUILDING FOR LIFE}

Parte do esforço do Reino Unido para aumentar os padrões de qualidade e sustentabilidade de seus espaços urbanos se concentrou na elaboração de políticas públicas e de diretrizes de projeto, a ideia era e continua sendo, promover o desenho urbano de qualidade através da influencia (diretrizes) e não somente apenas pelo controle (leis). Em 2000, foi criada a Comissão de Arquitetura e do Ambiente Construído 


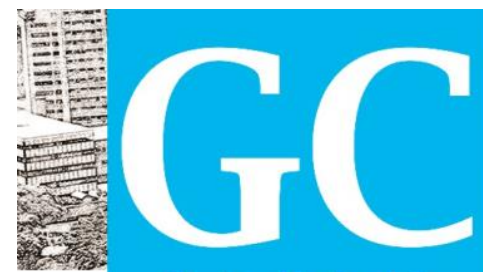

Revista Nacional de

Gerenciamento de Cidades

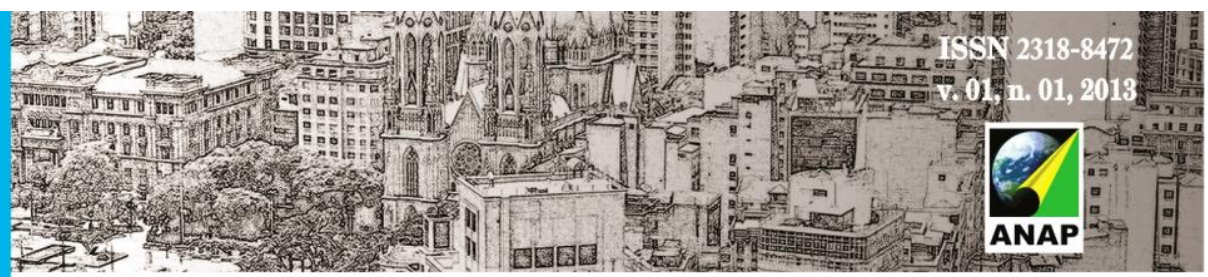

(Commission for Architecture and the Built Environment - CABE), justamente para ser "um vigia do desenho", criando, promovendo e divulgando diretrizes de boas práticas, conceitos e bons exemplos para profissionais, governos locais e pessoas em geral. Pois, segundo o CABE, existe a necessidade de mudar a percepção do que constitui um bom desenho e assegurar que esses princípios se estendam além da limitada imagem e objetivos marqueteiros, para uma resposta de qualidade. Através do CABE, ferramentas de avaliação e principalmente de divulgação de diretrizes de desenho de qualidade de espaços urbanos públicos e privados foram desenvolvidos, ampliando o leque conceitual e diferentes metodologias. ${ }^{1} \mathrm{Na}$ mesma época, o ConstructionIndustry Council (CIC), com o intuito de produzir um indicador de desempenho de edifícios, que identificaria os atributos que constituem qualidades de projeto, criou o Design Quality Indicator (DQI) ${ }^{2}$.

Em 2001, o CABE e a federação inglesa de construtores, patrocinados por algumas instituições envolvidas na produção do ambiente construído iniciaram um programa denominado Building for Life (BFL), com o objetivo de se tornar um referencial nacional para o desenvolvimento de vizinhanças, bairros e conjuntos habitacionais de qualidade, além de premiar e divulgar grandes exemplos. Em 2002 o site foi lançado e em 2005 publicaram o guia Building for Life: vinte perguntas que você precisa responder, que já esta em sua terceira edição.

Para o $\mathrm{BFL}$, assim como $\circ \mathrm{DQI}$, a base de um projeto de qualidade é o triangulo Vitruviano $^{3}$, mas, complementarmente seriam necessários para atingir tal objetivo, uma visão compartilhada e parcerias para o desenvolvimento desses espaços, pois a

\footnotetext{
${ }^{1}$ www.cabe.org.uk

${ }^{2}$ O DQI funciona como um sistema de duplo peso que primeiro permite a visualização dos resultados dependendo dos inúmeros aspectos de um edifício que são julgados. E depois é dividido em: fatores fundamentais (fundamental) que todo edifício deve atingir para funcionar, valor agregado (addesvalue) para indicar que o edifício irá gerar valor para as atividades a que se destina e excelência (excellence), que é atingida quando o projeto como um todo satisfaz os fatores fundamentais e agrega valor. (já citado anteriormente - SAXON, R., 2005, p18).

${ }^{3} A$ primeira tentativa reconhecida de identificar atributos genéricos de qualidade dos edifícios foi do romano Marcus VitruviusPollio, na sua obra De Architectura (aproxi.40 A.C.), que identificou três grandes princípios: "Firmitas" - Firminess (solidez, qualidade construtiva), "Commoditas" - commodity (funcionalidade, utilidade - utilitas?) e "Venustas" - delight (impacto nos sentidos, criar uma identidade, estética).
} 

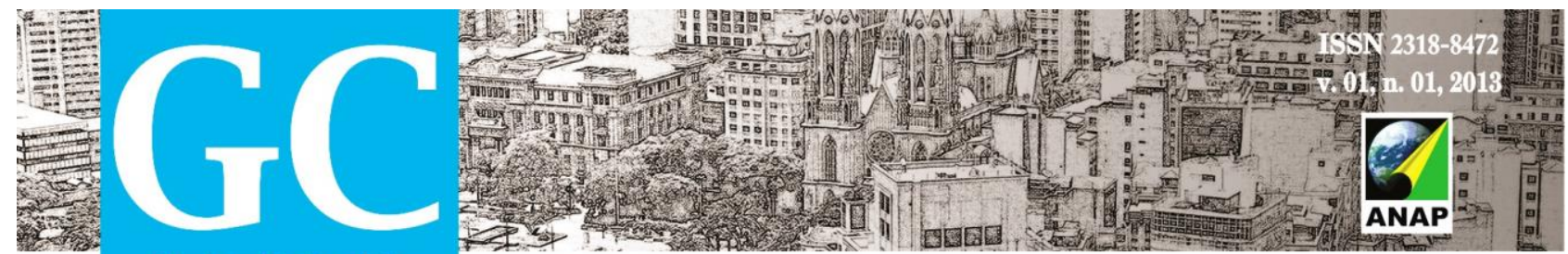

Revista Nacional de

Gerenciamento de Cidades

qualidade de projeto não está apenas relacionada a gostos subjetivos, mas sim, a funcionalidade, durabilidade e a qualidade visual e, o equilíbrio desses três objetivos não deveria adicionar custos ao projeto, porém esses custos seriam justificados.

Em sua primeira edição o guia foi divididos em quatro grandes grupos de questões, cada um com um tema específico: ambiente e comunidade; caráter; ruas, estacionamentos e pedestres e projeto e construção. Em cada grupo são apresentadas cinco perguntas que devem ser feitas olhando o conjunto habitacional a ser avaliado, se as respostas na maioria das vezes forem positivas esse empreendimento se caracteriza como um lugar de grande qualidade para se viver ${ }^{4}$.

O guia é dividido em duas grandes partes, a primeira explica cada um dos vinte critérios e aponta parâmetros chave que poderão ajudar a avaliar uma proposta de projeto e a segunda descreve e fornece exemplos de grupos diferentes de parâmetros e aponta 0 critério que irá fornecer mais informação sobre aquele assunto em específico. Cada critério da primeira sessão esta conectado a exemplos com evidências úteis da segunda sessão e vice e versa. ${ }^{5}$ Cada resposta às perguntas do guia pode valer um, meio ou nenhum ponto. Todos os interessados podem utilizar o guia para uma avaliação informal de um projeto ou empreendimento, mas o BFL, através de uma comissão julgadora, concede desde 2003 uma premiação para projetos habitacionais que atinjam mais de quatorze pontos, com a prata e de dezesseis a vinte pontos com ouro. Em 2010, foram cinquenta e cinco premiados, um deles foi o projeto da primeira fase do St. Andrews Bromley-by-Bow, em Londres, do escritório Allies \& Morrison Architects, um edifício linear organizado ao longo de um pátio interno, com 194 unidades habitacionais, das 964 previstas no projeto completo. Foi premiado com o BFL award e o BFL Silver standard (prata).

O projeto do St. Andrews esta localizado em uma área onde existia um grande

\footnotetext{
${ }^{4}$ http://webarchive.nationalarchives.gov.uk/20110107165544/http://www.buildingforlife.org/assessments/scori $\underline{\text { ng }}$ (27 de março de 2013)

${ }^{5} \mathrm{O}$ Building for life, foi estruturado com exemplos de projetos vencedores de concursos, é um guia que deve ser usado no computador, maiores informações e detalhes em www.buildingforlife.org
} 


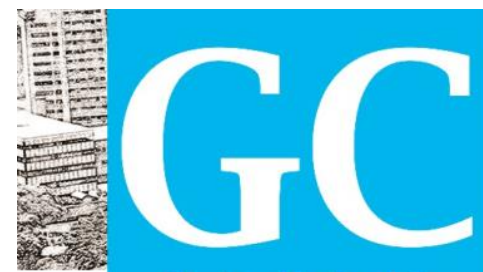

Revista Nacional de

Gerenciamento de Cidades

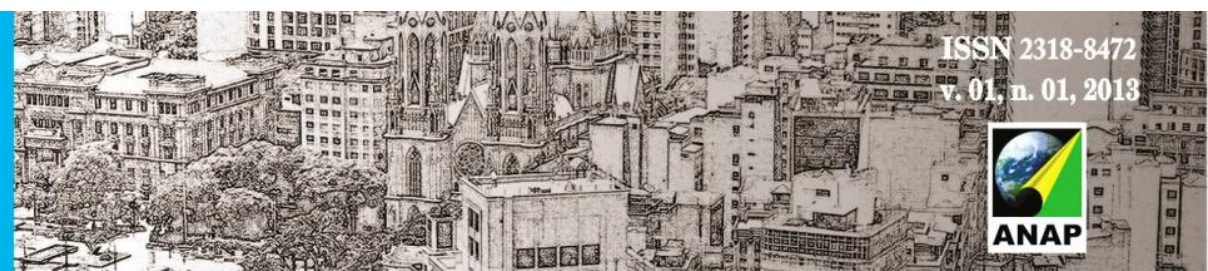

hospital desativado, próximo das instalações dos jogos Olímpicos de 2012, região estratégica para essa operação de regeneração urbana. A equipe envolvida no projeto procurou responder as necessidades dessa região leste de Londres, focando na carência habitacional, falta de serviços, facilidade e difícil acesso ao transporte público. Até 2013 todo conjunto deverá ser entregue, incluindo: parques, lojas e facilidades e a melhoria da conexão com os meios de transporte publico de Londres.

$\mathrm{Na}$ avaliação do BFL:

- Ambiente e comunidade: o empreendimento colocará a disposição de toda comunidade local lojas, parques e facilidades, incluindo um centro de saúde com capacidade para 10.000 pessoas. As conexões com o transporte publico serão fortalecidas, as unidades habitacionais tem grande diversidade de tamanhos e layout, que responde as necessidades da comunidade local e também poderá atrair novos moradores para a área, melhorando a variedade de pessoas no lugar. A localização dos parques, a demolição do antigo hospital e outras decisões importantes da implantação geral do conjunto, foram tomadas levando em consideração a opinião da comunidade local e dos grupos envolvidos no empreendimento.

- Caráter: o projeto oferece espaços públicos generosos e apesar de seus edifícios aparentarem uma unicidade, sua variedade de gabaritos, formas e detalhes confere ao conjunto grande grau de identidade. Para manter a relação de identidade da comunidade com o antigo hospital, elementos de arte criados junto com os alunos da escola local fazem parte do conjunto.

- Ruas, estacionamentos e pedestres: as ruas, o mobiliário urbano e o paisagismo foram pensados cuidadosamente priorizando o pedestre e os idosos, conferindo certo isolamento da confusão e do transito locais. As janelas e sacadas foram posicionadas de forma a oferecer uma vigilância natural aos espaços de encontro e as ruas. Não existe estacionamento no momento em função da boa oferta de transporte publico no local, porém esta previsto para o futuro. Novas conexões de 


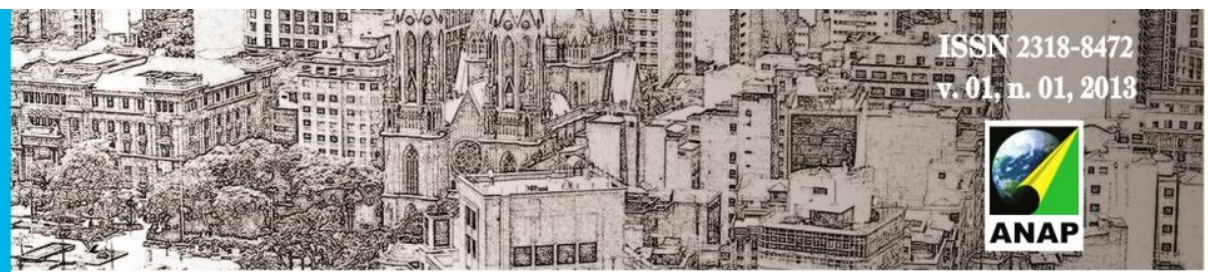

Revista Nacional de

Gerenciamento de Cidades

pedestre estão previstas para as outras estações de metro e trem da região, fortalecendo essa conexão com a cidade.

- Projeto e construção: os espaços públicos e seu paisagismo foram pensados em detalhe proporcionando um ambiente de qualidade, enfatizando entradas e protegendo o conjunto da estrada que fica ao lado. Internamente os pátios são projetados para o lazer e permanência dos moradores, com equipamentos urbanos e jardins, entrada de sol e bem conectados visualmente. Os materiais escolhidos conferem qualidade e identidade aos edifícios e a luz natural é abundante internamente.

St Andrews croqui vista aérea e vistas Internas (Fig. 01)
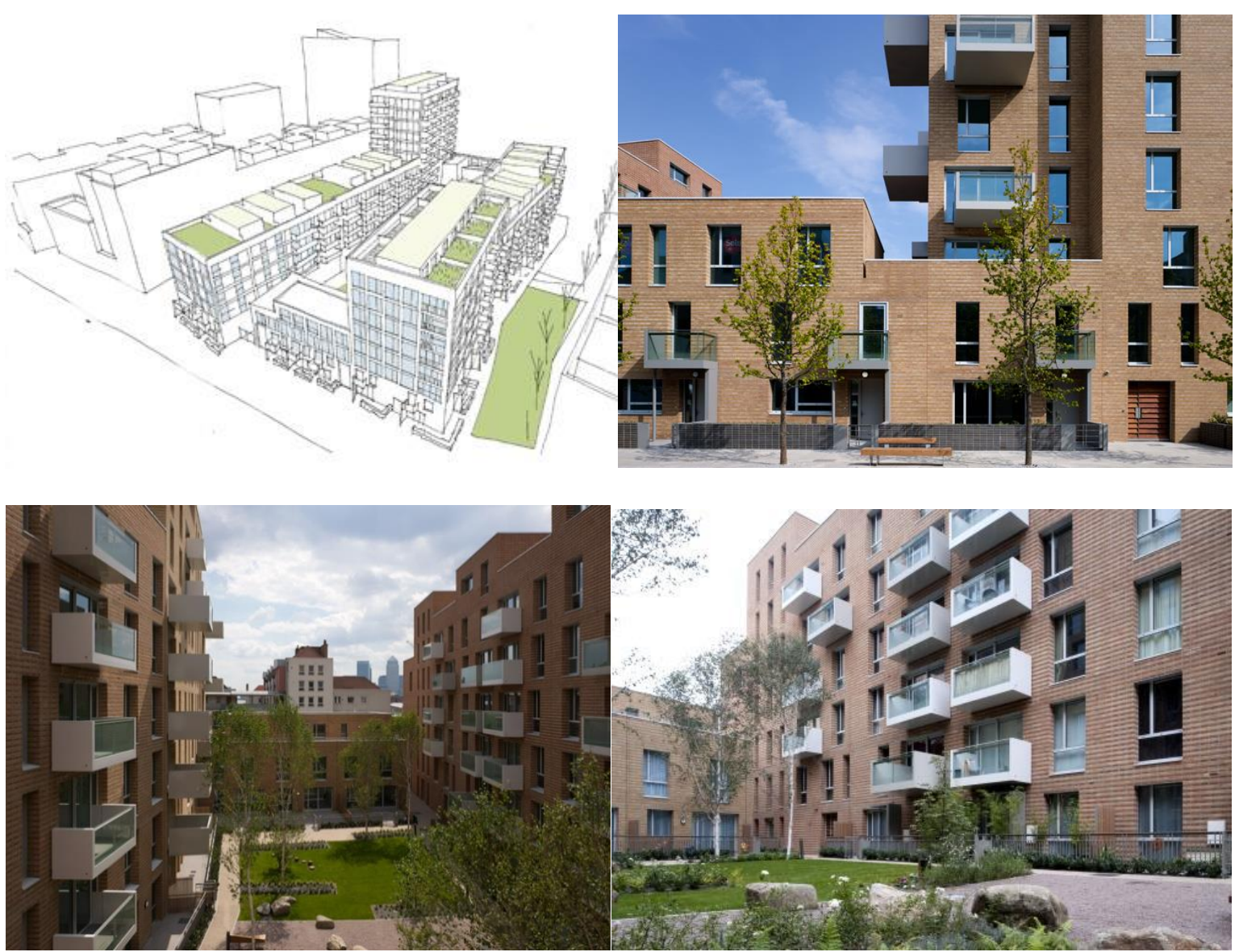


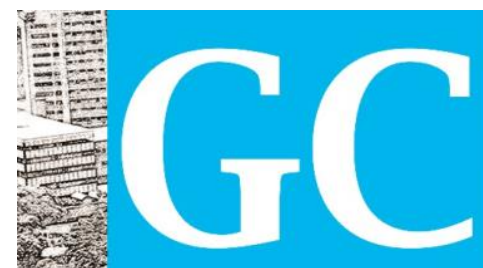

Revista Nacional de

Gerenciamento de Cidades

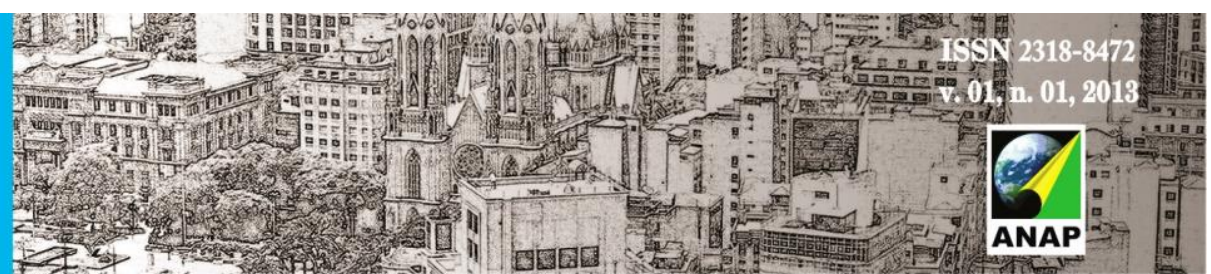

Fig. 01 - imagens St. Andrews

Fonte: http://webarchive.nationalarchives.gov.uk/20110107165544/http://www.buildingforlife.org/casestudies/st-andrews/photos ehttp://www.alliesandmorrison.com/projects/residential/2010/st-andrews-block-d/ (acesso em 27 de março 2013)

Outro projeto premiado foi o conjunto habitacional Stanmore Place, Harrow, do escritório de arquitetura GRID Architects, com o BFL award e o BFL Gold Standard(ouro),em sua primeira fase com 196 habitações de um total de 800 previstas no projeto, localizado na região nordeste de Londres.

Stanmore Place é um empreendimento de uso misto: apartamentos, casas, escritórios e pequenas lojas e tem grande potencial de se tornam um bairro referência de qualidade para a cidade. O terreno possuía uma série de dificuldades, entre elas, a possibilidade de alagamento que foi resolvida através de um projeto especifico de paisagismo, cujo programa deveria incluir habitações de interesse social.

$\mathrm{Na}$ avaliação do BFL:

- Ambiente e comunidade: esse ainda é um local de uso residencial, mas no futuro se tornará um lugar com variedade e vitalidade. É bem localizado, perto de serviços, facilidades e do transporte publico (estação de metrô) que o conecta com o restante da cidade, seu projeto oferece grandes possibilidades de misturas de pessoas e usos, além de apresentar uma boa solução para o terreno e suas especificidades.

- Caráter: o conjunto apresenta características marcantes, através do uso dos materiais e sua concepção formal, que confere identidade e caráter completando a paisagem local sem interferir de forma negativa, mas sim criando uma referencia positiva para região, seus prédios não passam de quatro andares, as ruas apresentam uma hierarquia em seu desenho, privilegiando o pedestre e possibilitando maior legibilidade.

- Ruas, estacionamentos e pedestres: o estacionamento dos carros esta resolvido 


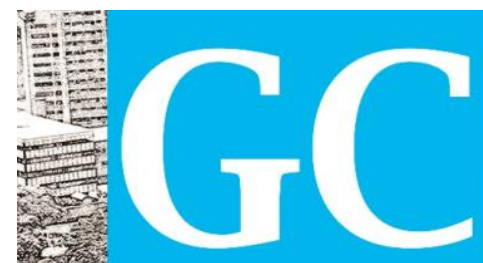

Revista Nacional de

Gerenciamento de Cidades

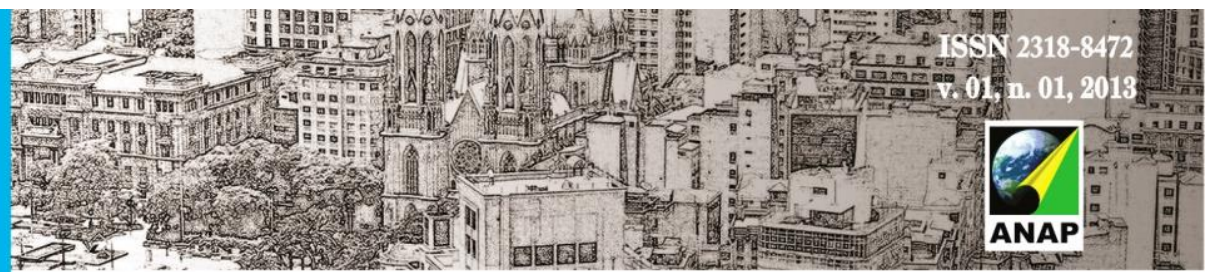

de forma racional e com um prédio de estacionamento, retirando os carros das ruas, liberando o espaço para o uso de todos, priorizando o lazer e o pedestre, as janelas são voltadas para as ruas tornando-as mais seguras.

- Projeto e construção: Os materiais foram cuidadosamente selecionados, com um leve predomínio do tijolo, as casas foram desenhadas de forma a demonstrar um ritmo ao longo da rua, tanto os telhados como as fachadas posteriores foram trabalhadas de forma diferenciada, quebrando a possibilidade de monotonia no conjunto. O projeto das unidades habitacionais limita possíveis ampliações e adaptações. Mesmo utilizando um método construtivo simples, seu padrão construtivo é de qualidade e de fácil manutenção.

Stanmore Place, Harrow implantação e imagens gerais (Fig. 02)

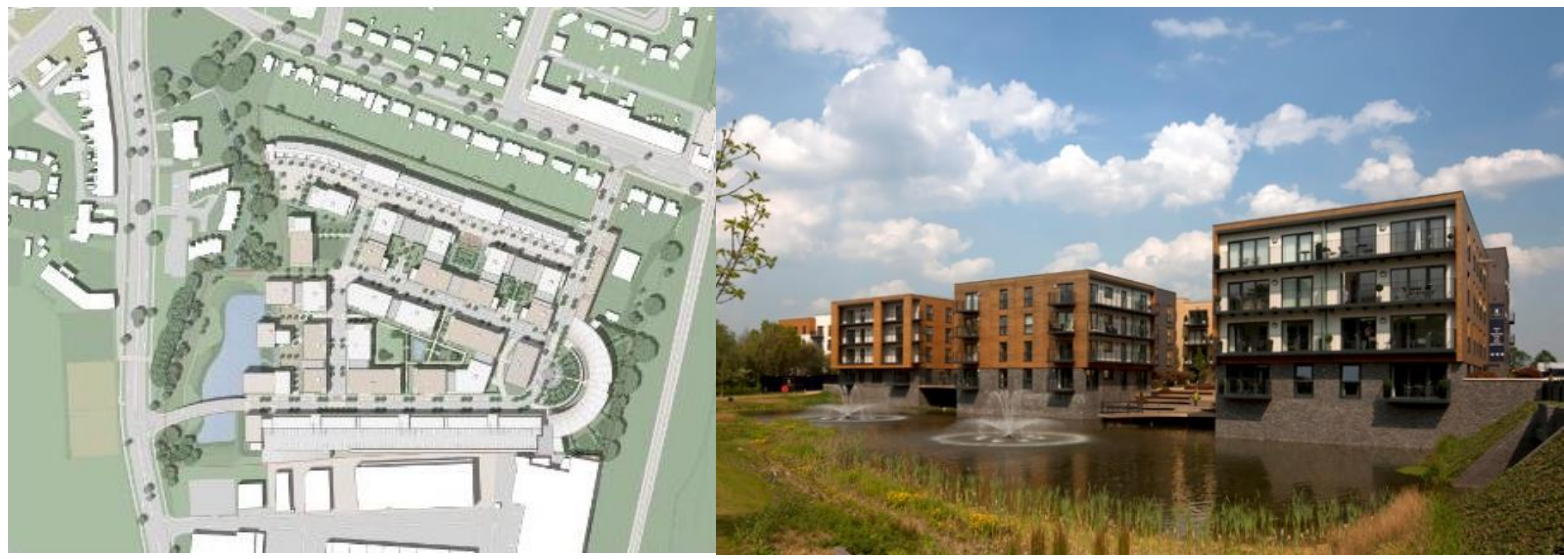

Fonte: http://www.gridarchitects.co.uk/projects/housing/stanmore-place-harrow-phase-1/ (acesso em 27 de março 2013) 


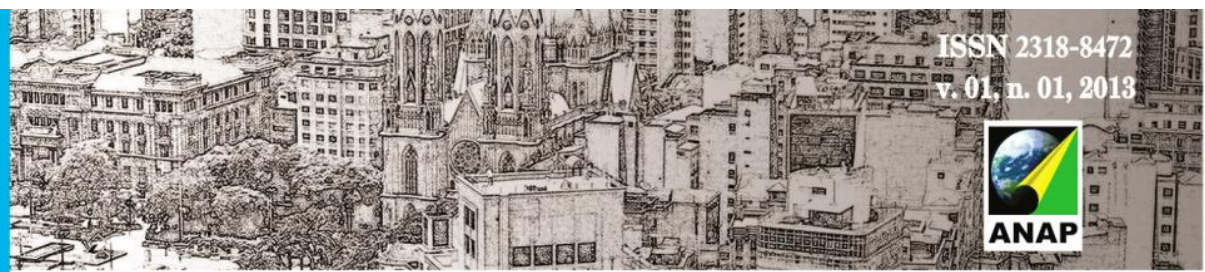

Revista Nacional de

Gerenciamento de Cidades

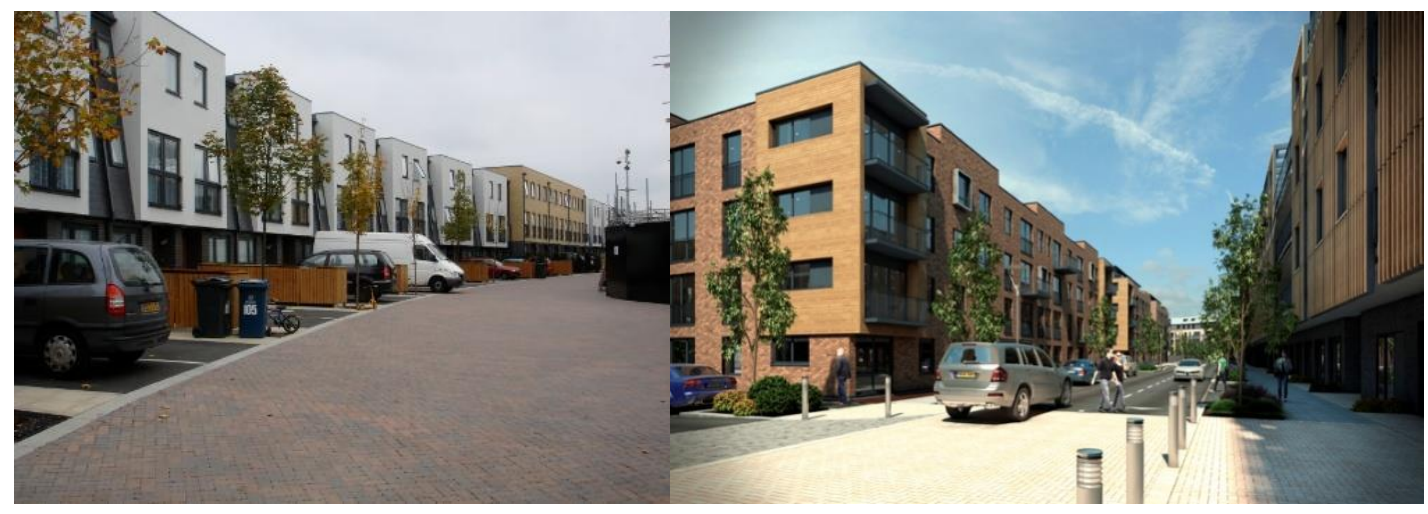

Fig. 02 - implantação e vista geral

Fonte: http://webarchive.nationalarchives.gov.uk/20110107165544/http://www.buildingforlife.org/casestudies/stanmore-place/photos (acesso em 27 de março 2013)

Guias como o Building for Life oferecem parâmetros de julgamento da qualidade do desenho urbano, para Carmona et al. (2003) é importante essa definição de qualidade do desenho urbano para a avaliação do valor agregado por ele às cidades, definindo assim parâmetros conceituais e de projeto que poderão ser julgados por todos os usuários do ambiente construído a fim de promover uma maior entrega de valor econômico, mas principalmente social e ambiental para a sociedade, a qualidade como forma de gerar valor.

\section{CONCLUSÃo}

Em situações onde projetos urbanosconseguiram de uma forma geral olhar toda a dimensão do conjunto proposto são premiados em iniciativas como o BFL, que se baseia em critérios claros que valorizam as questões abordadas no Desenho Urbano, estabelece-se que a sua presença e principalmente seu projeto cuidadoso podem sim agregar valor a todos os envolvidos: moradores, usuários, bairro e a cidade como um todo. Assim como o BFL aponta,o desenho urbano de qualidade agrega valor econômico melhorando a viabilidade dos empreendimentos, promovendo uma maior possibilidade de 


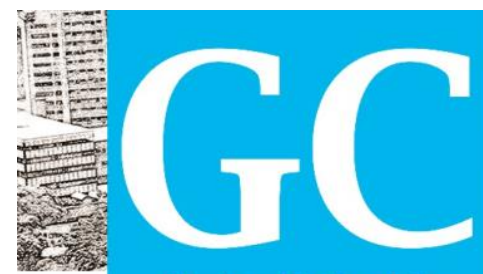

Revista Nacional de

Gerenciamento de Cidade

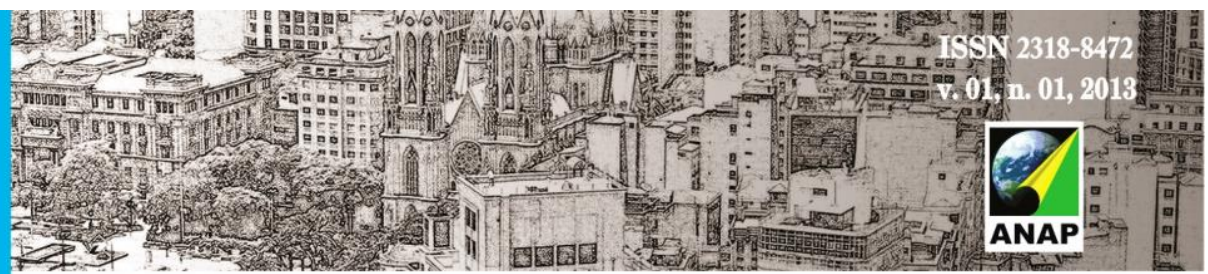

retorno financeiro, dando suporte aos elementos de uso misto, colocando o espaço construído acima dos padrões locais a um menor custo, respondendo às demandas dos usuários, contribuindo para melhorar o desempenho das relações sociais dos usuários, incentivando a regeneração urbana, contribuindo para a promoção do lugar, promovendo um diferencial e aumentando o prestígio da área e reduzindo os custos públicos de manutenção e possíveis reformulações e concertos do espaço urbano.

No geral, quando o desenho urbano é incluído de forma estratégica em todas as suas dimensões no processo de planejamento do ambiente construído, particularmente na integração do empreendimento dentro de infraestruturas já estabelecidas, ocorre uma maior entrega de valor, principalmente o valor social e ambiental, que são tão ou mais importantes que o valor econômico, produzindo espaços bem conectados, integrados ao seu contexto, inclusivos e acessíveis, com áreas de uso misto com variedade de facilidades e serviços para todos, com mais segurança, identidade e sentimento de pertencimento, contribuindo para melhorar a imagem do lugar, além da criação de espaços mais sustentáveis, da revitalização do acervo histórico urbano e promovendo a regeneração urbana do seu entorno próximo e da cidade em que está inserido (CARMONA ET AL. 2003, McINDOE ET AL. 2005).

Um bom desenho urbano pode gerar valor, porém para isso acontecer algumas barreiras precisam ser vencidas, como desmistificar a idéia de que um desenho urbano de maior qualidade necessariamente seja mais caro e divulgar as vantagens que ele oferece, tanto para empreendedores quanto para os usuários. Pesquisas sobre o valor do desenho urbano estão no início e ainda irão evoluir, pois alguns conceitos estão em processo de definição. Porém, a qualidade do desenho urbano já é considerada peça chave para se atingir a tão procurada renascença urbana, mas existe certa dificuldade em se definir o que é um bom desenho urbano e depois como fazer julgamentos objetivos relativos aos méritos de cada solução de projeto em particular, assim se torna necessário o desenvolvimento de parâmetros para uma visão mais completa do valor do desenho 


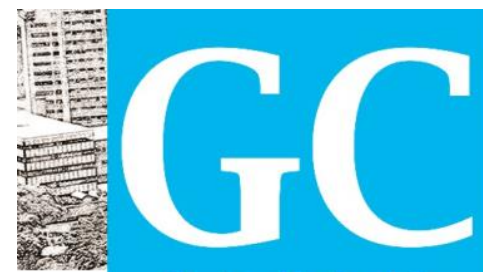

Revista Nacional de Gerenciamento de Cidades

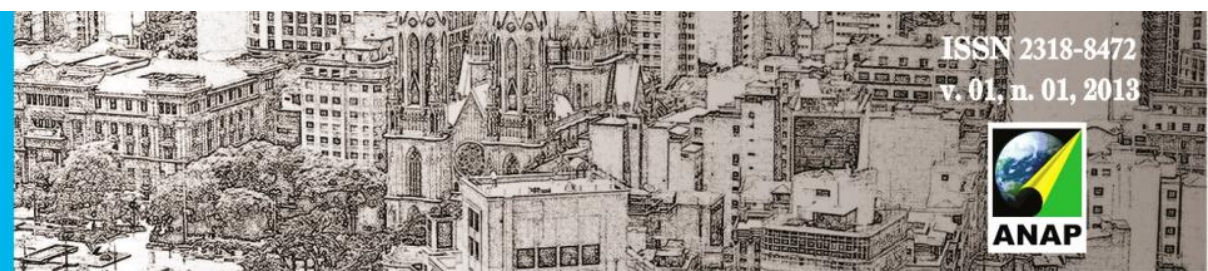

ANAP

urbano, buscando o desenvolvimento sustentável e a melhora da qualidade de vida (CARMONA ET AL. 2002).

\section{AGRADECIMENTOS}

Blind Review

\section{REFERÊNCIAS}

BENEDIKT, M. Value and Psychological Economics: An Outline, em Center 10: Value, Center for Study of American Architecture, University of Texas, Austin, 1997.

General Theory of Value: Synopsis,

http://www.utexas.edu/architecture/center/GenValu/GenValuSyn2.html (consultado em 08/04/2008)

In Towards a general theory of value: an interview with Michael

Benedikt, by Gonzo, in AIGA journal of Business and Design, New York, 2003.

http://www.aiga.org/content.cfm/towards-a-general-theory-of-value-an-interview-with-mi (consultado em 15/06/2007)

Workshop "Valor na habitação de interesse social", 07 e 08 de agosto de 2008, Departamento de Arquitetura e Construção, Faculdade de Engenharia Civil, Arquitetura e Urbanismo, UNICAMP, Campinas, 2008.

Notes in Supplement to "Human Needs and Economic Value in

Architecture," a lecture delivered at the UNICAMP Workshop on Social Housing, Campinas, Brazil, August 8, 2008; excerpted with footnotes omitted from Revaluing Architecture, being the Coda of A General Theory of Value (2006, unpublished).

CARMONA, M., HEATH, T. OC, T. TIESDELL, S. Public Places Urban Spaces -The Dimensions of Urban Design, Oxford: Architectural Press, 2003.

CARMONA, M. MAGALHÃES, C. EDWARDS, M. AWUOR, B. AMINOSSEHE, S. The Value of Urban Design, London: Thomas Telford, 2001. 


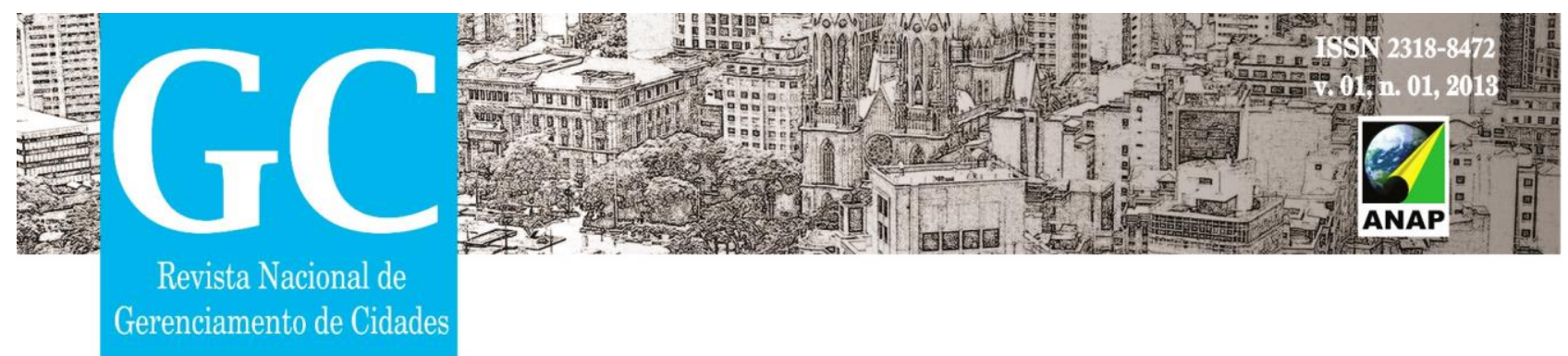

CARMONA, M. MAGALHÃES, C. EDWARDS, M. What value urban design? Urban Design International, vol.7, p.63-81, Londres, 2002.

CULLEN, G. The Concise Townscape.140 edição (primera edição 1961). Oxford: Architectural Press, 2006.

DEL RIO, V. Introdução ao desenho urbano no processo de planejamento, 1a edição, São Paulo: Editora Pini Ltda, 1990.

FERNANDES, A. M. DOS S. 2 Gênese, evolução e tendências contemporâneas do desenho urbano. Malha urbana - Revista Lusófona de Urbanismo, no 8, 2009. http://revistas.ulusofona.pt/index.php/malhaurbana/issue/view/118 (consultado em 31/03/2011)

GRANJA, D. et al. A Natureza do Valor Desejado na Habitação Social, Ambiente Construído, Porto Alegre, v. 9, n. 2, p. 87-103, abr.jun. 2009.

JACOBS, J. The Death and Life of Great American Cities, London: John Dickens and Conner Ltd. 1961.

MACEDO, A. C. A carta do Novo Urbanismo norte-americano. Arquitextos, São Paulo, 07.082, Vitruvius, mar.2007 http://vitruvius.com.br/read/arquitextos/07.082/262 (consultado em 18/06/2010)

O Novo Urbanismo na Europa. Arquitextos, São Paulo, 08.094, Vitruvius, mar.2008. http://vitruvius.com.br/read/arquitextos/08.094/158 (consultado em 16/03/2011)

McINDOE, G. ET AL. The value of Urban Design, the economic, environmental and social benefits of urban design, New Zealand: publishes by the Ministry for the Environment Manatu Mo Te Taiao, Welllington, 2005. www.mfe.govt.nz

MACMILLAN, S. The value handbook, London: Commission for Architecture and the Built Environment (CABE), 2006.

MIRON, L. I. G. Gerenciamento dos Requisitos dos Clientes de Empreendimentos Habitacionais de Interesse Social: proposta para o programa integrado entrada da cidade em Porto Alegre, RS. 2008. 351 f. Tese (Doutorado em Engenharia) - Programa de Pós-Graduação em Engenharia Civil, Universidade Federal do Rio Grande do Sul, Porto Alegre, 2008.

SAXON, R. Be Valuable: a guide to creating value in the built environment. Londres: Constructing Excellence, 2005. 


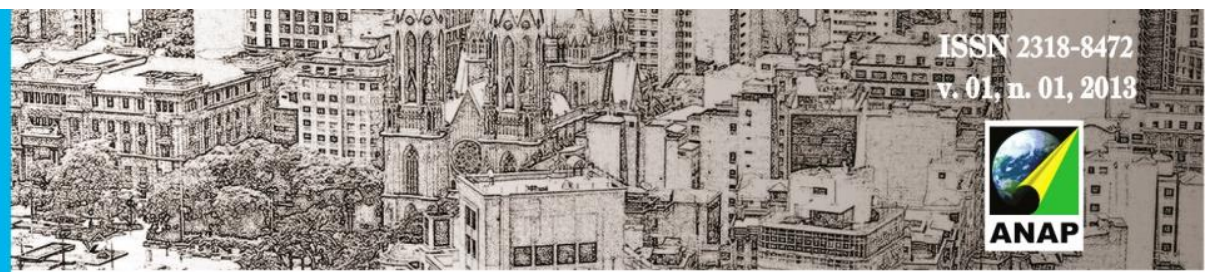

Revista Nacional de

Gerenciamento de Cidades

THOMSON, D. S. ET AL. Managing Value and quality in design, Building Research \& Information, London, v. 31, n. 5, p.334-345, set. 2003. Bimestral.

http://webarchive.nationalarchives.gov.uk/20110107165544/http://www.buildingforlife.org/c ase-studies(27 de março de 2013)

http://www.gridarchitects.co.uk/projects/housing/stanmore-place-harrow-phase-1/ (27 de março de 2013)

http://webarchive.nationalarchives.gov.uk/20110107165544/http://www.buildingforlife.org/c ase-studies/stanmore-place/photos(27 de março 2013)

http://webarchive.nationalarchives.gov.uk/20110107165544/http://www.buildingforlife.org/c ase-studies/st-andrews/photos(27 de março de 2013)

http://www.alliesandmorrison.com/projects/residential/2010/st-andrews-block-d//27 de março de 2013) 